\title{
Gasification of corn and clover grass in supercritical water
}

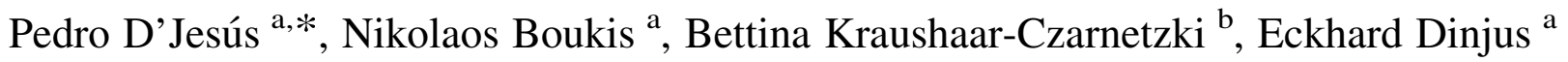 \\ ${ }^{a}$ Institut für Technische Chemie, Chemisch-Physikalische Verfahren (ITC-CPV), Forschungszentrum Karlsruhe, Germany \\ ${ }^{\mathrm{b}}$ Institut für Chemische Verfahrenstechnik, Universität Karlsruhe, Karlsruhe, Germany
}

Received 8 March 2005; received in revised form 29 September 2005; accepted 18 October 2005

Available online 28 November 2005

\begin{abstract}
The influence of pressure, temperature, residence time, and alkali addition on the gasification of corn starch, clover grass and corn silage in supercritical water was investigated. Changing the pressure did not alter the gasification yield. An increase in the temperature notably improved the conversion of biomass. Residence time variations revealed that with longer residence time, gasification yield was improved until a maximum was reached. Gas composition changed with residence time and temperature. Potassium addition affected the gasification yield of corn starch, but did not influence the gasification yield of the potassium-containing natural products of clover grass and corn silage.
\end{abstract}

(C) 2005 Elsevier Ltd. All rights reserved.

Keywords: Biomass; Supercritical water gasification; Hydrogen

\section{Introduction}

To reduce the contribution of carbon dioxide in the global greenhouse effect, the actual consumption of fossil fuels has to be decreased. To this aim, regenerative energy sources like biomass have been investigated extensively. Compared to other biomass energy conversion technologies, supercritical water gasification (SWG) is the most efficient one for biomass with a high moisture content $(>40 \%)$ [1]. In spite of the high pressure and the high temperature needed for the biomass conversion with supercritical water the process is technical feasible, because tubular or slim vessel type reactors can be used.

Calzavara et al. [2] evaluated the supercritical water gasification process for hydrogen production. They found that the energy efficiency reached $60 \%$ without including energy recovery. With energy recovery, the overall energy yield reached $90 \%$. Economical evaluation of this process can be found also in the literature. Matsumura et al. [3] calculated that the cost of the product gas of the supercritical water gasification process is 1.86 times more expensive than city gas in Tokyo.

Biomass reacts with water according to the ideal reaction (1)

$$
\mathrm{C}_{6} \mathrm{H}_{12} \mathrm{O}_{6}+6 \mathrm{H}_{2} \mathrm{O} \rightarrow 6 \mathrm{CO}_{2}+12 \mathrm{H}_{2}
$$

\footnotetext{
* Corresponding author. Tel.: +49 7247824845; fax: +49 7247822244 .

E-mail address: pedro.djesus@itc-cpv.fzk.de (P. D’Jesús).
}

Hydrogen is released from both water and biomass. The reaction (1) is not complete and methane, $\mathrm{CO}$, and some higher hydrocarbons are formed. $\mathrm{CO}$ formation is inhibited at higher temperature, because $\mathrm{CO}$ conversion by the water-gas shift reaction is favored [4]. The reactions mechanism under conditions at high density and high water concentration is not known. Kruse et al. [5] proposed a possible reaction mechanism, where the biomass degraded to intermediates (aldehyds, etc) before gases are formed. The degradation of Biomass is fast and the intermediate products cannot be determined. Biomass also contains a lot of impurities, which could affect the reactions. All reactions took place in one process step.

The influence of process variables like temperature pressure, residence time, and catalyst on supercritical water gasification of model compounds has been investigated. At high temperatures the best hydrogen yield for the supercritical water gasification of sawdust and different starches was reached [6]. The same important effect of the temperature has been reported in other publications [7-10]. The pressure has no great effect on the glucose gasification efficiency and the fraction of the gas product [8]. A decrease of pressure leads to an increase of hydrogen formation [5]. Carbon conversion does not vary at a longer residence time. The efficiency was observed to be decreased by a shorter residence time $[7,8]$. In batch experiments, the reaction time had a strong influence on the gas yield [11,12].

The addition of potassium salts in the reaction of biomass model compounds with supercritical water favored the $\mathrm{CO}$ 
conversion through the water-gas shift reaction. This increased the hydrogen yield [5]. The addition of alkali inhibited char formation [13]. This effect was of minor importance in case of real biomass gasification in supercritical water [14].

Use of noble metal catalysts was investigated in order to increase lignin conversion. Ruthenium catalysts were more active compared to other metals [15]. With a ruthenium catalyst, the lignin and cellulose conversion were 30 and $70 \%$, respectively [16]. The lifetime of a catalyst in supercritical water gasification of real biomass is problematic because of all the contaminants existing in real biomass, such as sulfur etc.

As feedstock of the supercritical water gasification process, two kinds of feedstock are though: organic waste, like sewage sludge, and energetic plants like corn. Clover grass can be gathered all the year, and represents a waste. Corn is one of the most cultivated plants all around the world. It is adapted to almost any climate and its cultivation does not require any extreme conditions. Corn has a high energy content and high organic matter yield (per hectare) [17]. Corn silage is chemically stable, it does not degrade and maintains its properties over long periods of time. Corn silage is available during all the year, for this reason shortages in the continuous production of hydrogen from biomass is prevented. Because of all these advantages, corn silage is a feedstock suitable for an industrial supercritical water gasification process.

To optimise the process of supercritical water gasification of biomass, the influence of the process variables on the gasification of real biomass feedstock like corn has to be investigated. In this paper, it is reported about the effects of temperature, pressure, residence time, and use of potassium on the gasification of corn starch, clover grass, and corn silage. This paper provides new results for the gasification of natural biomass educts in supercritical water.

\section{Experimental}

\subsection{Preparation of educts}

Working with real biomass is associated with a lot of hurdles that have to be overcome; one being the preparation of a pumpable educt. In this project, we used corn starch, clover grass, and corn silage as biomass samples.

Starch was acquired from Carl Roth GmbH. Corn starch was used to demonstrate functioning of the equipment before working with real biomass and evaluating the influence of potassium on the gasification efficiency. A water-starch gel was prepared at $370 \mathrm{~K}$. Potassium (in the form of $\mathrm{KHCO}_{3}$ ) was added to the mixture of starch and water before the formation of the gel. Xanthan was used as thickening agent in the preparation of pumpable mixtures of water and biomass. Its optimal proportion in the reaction mixture was about $0.25 \mathrm{wt} . \%$, with this concentration no separation of the biomass and water was observed. Table 1 shows the composition of the biomass used in this work. The biomass was crushed until a particle size less than $1 \mathrm{~mm}$, before the educt was prepared.

The pressure tank was charged with the prepared biomass. For this purpose, a flexible tube pump was used. To prevent the fermentation of the biomass during the summer, the container was equipped with a cooling system. The fermentation of the solution led to the agglomeration of particles and, consequently, plugging of the system was observed

\subsection{Apparatus}

A continuous flow reactor was used to investigate the gasification of real biomass. The reactor material was the nickel alloy Inconel 625 . The reactor wall was treated once with a solution of $\mathrm{H}_{2} \mathrm{O}_{2}$ in water ( 3 wt. \%) at $873 \mathrm{~K}$ and $25 \mathrm{MPa}$ for about $50 \mathrm{~h}$ after installation (see also Section 3 ).

The first experiments in the high-pressure equipment were performed with a horizontal reactor $(1700 \mathrm{~mm}$ long, $8 \mathrm{~mm}$ inner diameter), as shown in the flow diagram (Fig. 1). A downflow reactor $(1000 \mathrm{~mm}$ long and $8 \mathrm{~mm}$ inner diameter) with preheater ( $250 \mathrm{~mm}$ long and $8 \mathrm{~mm}$ inner diameter) was used for the investigation of the influence of temperature on the gasification of corn silage with the aim of improving gasification yield and reducing the problems of solid formation. The reactor was heated up to a maximum temperature of $973 \mathrm{~K}$ by heating coils. The equipment comprised several temperature control units. Temperature profiles were measured in order to optimize the set values of each temperature control system. The connections were cooled down by a chiller. A pressure tank was needed to store the prepared biomass; inside, a piston was installed, which acted as a pump driven by water. With an HPLC pump, water was compressed to system pressure at the desired flow. A maximal pressure of $45 \mathrm{MPa}$ was permitted. Pressure was controlled by a back-pressure regulator (Tescom). After the expansion, the reactor's products were separated into two phases: liquid and gas. The separation took place in a glass recipient, from where the gas and liquid samples were taken.

Solid components like corrosion products and carbon-containing matter result in plugging problems. To reduce plugging, washing with highly pressurized water was performed after

Table 1

Elemental composition (in wt $\%$ on dry matter) of biomass educts

\begin{tabular}{llllllllllll}
\hline Educt & $\mathrm{C}$ & $\mathrm{O}$ & $\mathrm{H}$ & $\mathrm{N}$ & $\mathrm{K}$ & $\mathrm{S}$ & $\mathrm{Si}$ & $\mathrm{Ca}$ & $\mathrm{P}$ & $\mathrm{Cl}$ & $\mathrm{Fe}$ \\
\hline $\begin{array}{l}\text { Corn } \\
\text { starch }\end{array}$ & 44.44 & 49.34 & 6.22 & 0 & 0 & 0 & 0 & 0 & 0 & 0 \\
$\begin{array}{l}\text { Clover } \\
\text { grass }\end{array}$ & 44.90 & 43.3 & 6.8 & 2.2 & 1.1 & 0.3 & 0.17 & 0.64 & 0.32 & 0.12 \\
$\begin{array}{l}\text { Corn } \\
\text { silage }\end{array}$ & 43.40 & 46.70 & 6.17 & 1.02 & 0.98 & 0.93 & 0.35 & 0.20 & 0.14 & 0.13 & 0.13 \\
\hline
\end{tabular}




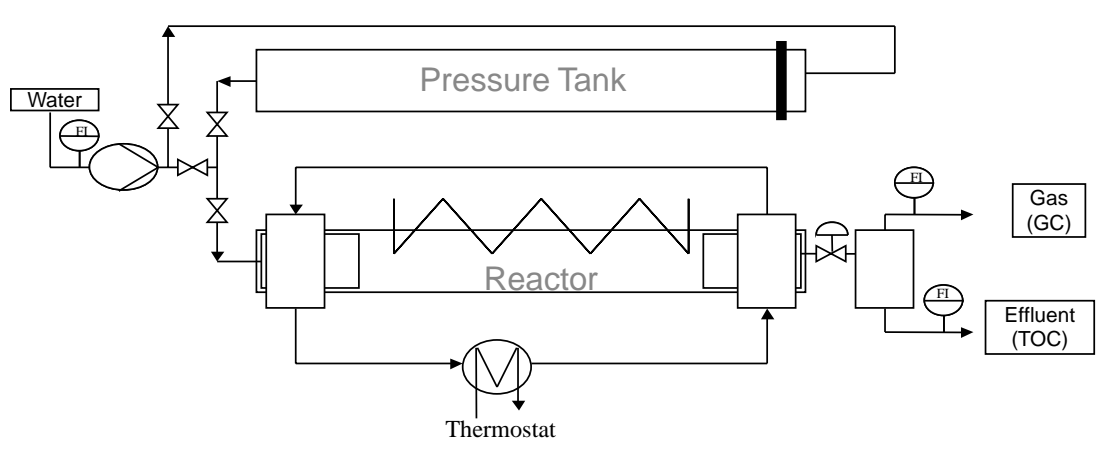

Fig. 1. High-pressure laboratory equipment for supercritical water gasification of real biomass.

each experiment. The plugging problem could be suppressed with this treatment.

\subsection{Analysis}

Gas composition was measured with a GC HP 6890 with two columns (80/100 Hayesep Q, $2 \mathrm{~m}$ long and 60/80 Molesieve $5 \AA$, $4 \mathrm{~m}$ long), one for $\mathrm{H}_{2}$ and the second one for $\mathrm{CO}_{2}$, hydrocarbons, and helium as carrier gas. Concentration was measured by a thermal conductivity and flame ionization detector which were connected in series. The total organic carbon (TOC) and total carbon (TC) contents in the reactor liquid effluent were determined with a TOC analyzer (Rosemount Dohrmann DC-190). One gas flow meter (Ritter) and two balances (Sartorius) were used to estimate the educt, gas product, and aqueous effluent flows.

\subsection{Data interpretation}

Three parameters shall be discussed in the following chapter: gasification yield, carbon content in the effluent, and carbon production. Instead of total organic carbon (TOC), total carbon (TC) is used to represent the carbon content of the aqueous reactor effluent in the discussion, because this value covers all carbon (organic and inorganic) existing in the effluent, which is needed to close the carbon balance.

Gases produced are hydrogen, carbon dioxide, carbon monoxide, methane, and ethane. At ambient temperature and pressure, i.e. after pressure relief, these can be considered ideal gases.

The gasification yield $(Y)$ is defined as:

$Y=\frac{\sum_{i} \alpha_{i} C_{i} \frac{p \dot{V}}{R T} M}{w \dot{m}}$

$C_{i}$ Concentration of component ' $\mathrm{i}$ ' in the gas product [vol\%]

$\alpha_{i}$ Number of carbon atoms of component ' $i$ ' in the gas product

$\dot{m}$ Feed flow (g/min)

$M$ Molar mass of carbon $(\mathrm{g} / \mathrm{mol})$

$p$ Pressure $(\mathrm{Pa})$

$R$ Universal constant of gases

$T$ Temperature (K)
$\dot{V}$ Gas flow under ambient conditions (1/min)

$w$ Carbon concentration in the feed (wt.\%)
$P=\frac{\dot{V}}{w \dot{m}}$

$P$ Gas production (l gas/g $\mathrm{C}$ in educt)

Variables to be defined for the following discussion shall be the residence time and space time. For the calculation of the residence time, variation of density of the main component (water) with temperature along the reactor is considered. For the space time, flow is considered to be constant.

Residence time is defined as:

$\tau=\frac{V}{\dot{V}_{i}}$

\author{
$\tau$ Residence time (min) \\ $V$ Reactor volume (1) \\ $\dot{V}_{i}$ Internal flow under reaction conditions (1/min)
}

Space time (min) is defined as:

Space Time $=\frac{V}{\dot{V}_{o}}$

$\dot{V}_{0}$ Educt flow under ambient conditions (1/min)

\section{Results and discussion}

The reactor material used was Inconel 625. Yu et al. [18] found that the wall of a reactor made of Inconel catalyzed the water-gas shift reaction. Boukis et al. [19] studied the catalytic role of the heavy metals of the reactor material in methanol reforming in supercritical water. The inner surface of the reactor was mainly covered with $\mathrm{NiO}$ after a reaction with $3 \%$ $\mathrm{H}_{2} \mathrm{O}_{2}$ solution at $873 \mathrm{~K}$. Chromium and molybdenum were dissolved selectively and removed from the surface. The concentration of these metals in the effluent increased with temperature (7-10 times higher at $873 \mathrm{~K}$ than at $773 \mathrm{~K}$ ). The dissolution of $\mathrm{Cr}$ and Mo led to an increased Ni concentration 
on the reactor surface. During the subsequent gasification reaction, the nickel oxides formed were reduced to $\mathrm{Ni}$. These composition changes of the inner surface of the reactor accelerated methanol decomposition and the water-gas shift reaction. For these reasons, the reactor wall was treated with a solution of $\mathrm{H}_{2} \mathrm{O}_{2}$ for each newly installed reactor. It is known from previous work that in the process of biomass gasification, hydrogen production predominates as compared to methane and carbon dioxide. Our observations with real biomass provide new information about this process.

\subsection{Corn starch gasification}

The first experiments were done with corn starch. Potassium (in the form of $\mathrm{KHCO}_{3}$ ) was added to the mixture of starch and water in order to investigate the effect of potassium in supercritical water gasification. This catalyst was added before the formation of the gel. With increasing potassium concentration from 0 to $500 \mathrm{ppm}$, the gasification yield rises from 0.82 to 0.92 . Further increase in potassium concentrations up to 3000 ppm does not improve the gasification yield significantly. It is also shown that the carbon concentration (TC) in the reactor effluent increases with the potassium concentration. The positive effect of potassium addition on the gas yield has been described in literature as a catalytic effect of potassium in the water-gas shift reaction. When studying the gasification of $5 \mathrm{wt} . \%$ pyrocatechol at $773 \mathrm{~K}$, Kruse et al. [5] found that the $\mathrm{CO}$ concentration in the gas product dropped from more than $40 \mathrm{vol} \%$ to less than $1 \mathrm{vol} \%$, while the amount of $\mathrm{KOH}$ increased from 0 to $5 \mathrm{wt} \%$. The hydrogen content in the gas product rises by up to three times with an increasing potassium amount in the reaction mixture. Sinag et al. [20] explained the catalytic effect of potassium by the formation of formate salt. $\mathrm{CO}$ reacts with $\mathrm{KOH}$ to a formate salt (HCOOK), which reacts further with water to produce hydrogen.

The temperature is the most important process variable, as is demonstrated in Fig. 2 by the strong influence of temperature on the gas yield. As was expected because of the energy needed to complete the endothermic reforming reaction of biomass, the gasification yield rises from 0.41 to 0.92 with the temperature increasing from 823 to $973 \mathrm{~K}$. The same positive effect is reflected by the TC content in the effluent, which

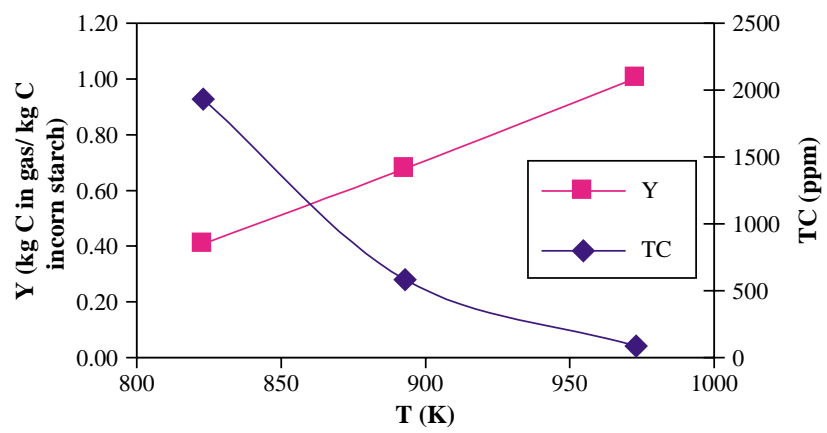

Fig. 2. Influence of temperature on the gasification yield $(Y)$ and total carbon content of the liquid effluent (TC) in the supercritical water gasification of starch at $p=25 \mathrm{MPa}, \dot{m}=3 \mathrm{~g} / \mathrm{min}, 5 \mathrm{wt} \% \mathrm{DOM}$, and $500 \mathrm{ppm} \mathrm{K}$. decreases strongly with temperature. Higher temperatures could not be investigated because of the limited strength of the reactor material at high temperatures (1023-1073 K).

Antal et al. [6] also investigated the gasification of corn starch in supercritical water with a carbon catalyst. They reported that carbon conversion increased from 0.91 at $963 \mathrm{~K}$ to 1.06 at $1078 \mathrm{~K}$, flow rates varied $(1-4.0 \mathrm{~g} / \mathrm{min})$. These reported results are similar to those presented in this work.

\subsection{Clover grass gasification}

Clover grass was gathered from the adjacencies. After its size reduction, it was used to demonstrate the process with waste biomass.

The experiments with clover grass also reveal a strong dependence of the gas yield on the temperature (Table 2). The gasification yield increased from 0.62 to 0.88 and the carbon concentration of the effluent (TC) decreased from 1017 to 333 ppm with increasing temperature from 898 to $973 \mathrm{~K}$. This means that the conversion of the biomass carbon was improved with increasing temperature. Compared to the results obtained with a simpler biomass like corn starch at the highest temperature $(973 \mathrm{~K})$, the maximum conversion reached was smaller by $4 \%$. The main product was hydrogen (40 vol\%). See also [21].

Influence of potassium addition on the gasification of real biomass has also been investigated. It is known that real biomass, like clover grass, contains approximately about $1 \mathrm{wt} \%$ of potassium (based on dry matter biomass), which is equivalent to $500 \mathrm{ppm}(\mathrm{K})$ for $5 \mathrm{wt} \%$ (dry matter) biomass concentration (see Table 2). Further potassium addition does not influence the gas production $(3.221 \mathrm{gas} / \mathrm{g} C$ without $K$ at $973 \mathrm{~K})$. Kruse et al. [14] also found that the addition of potassium did not influence the gasification yield in case of supercritical water gasification of wood and straw.

\subsection{Corn silage gasification}

In the subsequent experiments, corn silage was chosen as feedstock. The influence of process variables like pressure, temperature, and residence time was investigated.

In literature it was reported that the gasification yield and the solid formation decreased with pressure when using a model substance [5]. In our experiments, the gasification yield of corn silage was studied as a function of the pressure. The amount of gas produced does not vary with changing process

Table 2

Influence of the temperature on gasification yield $(Y)$, production $(P)$, and carbon content in the effluent (TC) during the supercritical water gasification of clover grass

\begin{tabular}{llll}
\hline$T(\mathrm{~K})$ & $Y(\mathrm{~kg} \mathrm{C}$ gas/kg C & $P(1$ gas $/ \mathrm{g} \mathrm{C})$ & TC $(\mathrm{ppm})$ \\
\hline 898 & educt $)$ & & \\
923 & 0.62 & 2.49 & 1017 \\
973 & 0.77 & 2.87 & 698 \\
\hline
\end{tabular}

$p=250$ bar, $5 \mathrm{wt} \%$ clover grass, flow rate $=3 \mathrm{~g} / \mathrm{min}$, and $100 \mathrm{ppm} \mathrm{K}$. 
pressure $(2.70 \pm 0.011 \mathrm{gas} / \mathrm{g} C$ in corn silage) The lacking effect of the pressure on the gas production was described by a thermodynamic calculation according to Feng [22]. The effect of pressure on the driving force of the reaction $(-\Delta G$, Gibbs' free energy) is negligible [22].

Another variable to be investigated is the residence time. In these experiments the down flow reactor was used. The reactor configuration was changed in order to improve biomass conversion. Fig. 3 shows the results of the variation of the residence time. When calculating the residence time, the strong changes in density near the critical point of water have to be considered. For this purpose, temperature profiles were measured along the reactor when it was operated with water. In case of biomass operation, the inner capillary was corroded and could not be use anymore For better comparisons a modified residence time (space time) was used, which is calculated under input-output conditions (ambient conditions).

The yield curve in Fig. 3 illustrates the influence of the residence time on the supercritical water gasification of biomass. If the $y$-curve was prolonged to axes intersection, a linear increase of the gasification yield could be observed with increasing residence time until a region (Space Time $>9 \mathrm{~min}$ ), where no increase takes place anymore, which is probably due to the fact that most of the organic matter $(>90 \%)$ has been gasified and the residues cannot be converted into gas. The description of the residence time dependence is important for the optimization of this process and the future design of industrial supercritical water gasification plants.

The tubular reactor can be approximated to an ideal plugflow reactor. For the idealization, the following criteria have to be fulfilled:

$\mathrm{Pe}=\frac{u d}{D} \rightarrow \infty$

Pe Peclet number

$u$ Axial velocity $(\mathrm{m} / \mathrm{s})$

$d$ Reactor diameter $(\mathrm{m})$

$D$ Axial dispersion coefficient $\left(\mathrm{m}^{2} / \mathrm{s}\right)$

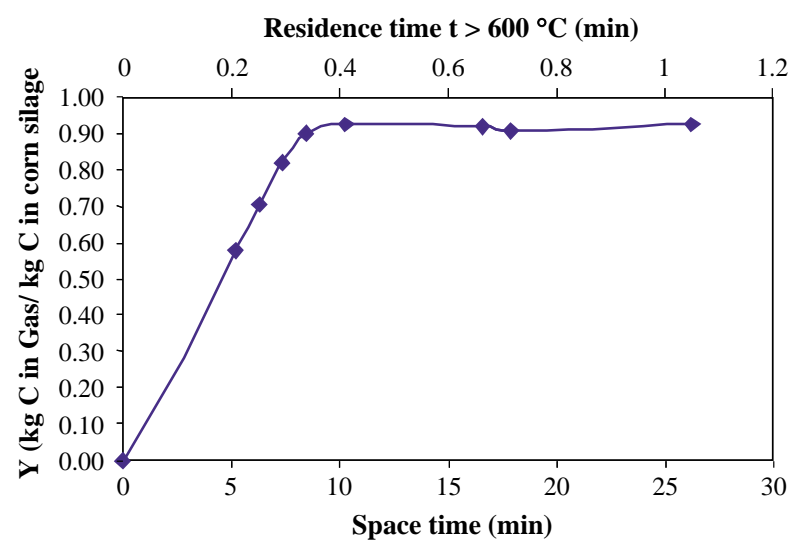

Fig. 3. Gasification yield $(Y)$ as a function of space time and residence time at $T=973 \mathrm{~K}, p=25 \mathrm{MPa}, 5 \mathrm{wt} \%$ corn silage (DOM).
When the length/diameter ratio $(L / d)$ is higher than 100 , the axial dispersion coefficient tends to zero and can be neglected as it is expressed in (7).

$\frac{L}{d} \geq 100 D \rightarrow 0$

In our experiments, the $L / d$ factor was larger than 100 . In this case, the axial dispersion coefficient can be neglected. When the axial dispersion approaches zero, then the Pe Number tends to infinity and the simplification of an ideal plugflow reactor is valid. With this simplification, the reaction can be modeled by the Eq. (8).

$\frac{\mathrm{d} \tau}{\mathrm{d} y}=\frac{C_{0}}{-r_{C}}$

where

$C_{0}$ Initial concentration of carbon in the feed (mol/l)

$r_{C}$ Reaction rate of carbon $(\mathrm{mol} / \mathrm{l})$

From the yield curve in Fig. 3, a first approximation of the kinetics for a concentration of $5 \mathrm{wt} \%$ results in zero-order kinetics, because the gasification yield is linearly dependent on the residence time until it reaches a maximal value. In order to obtain such a linear dependence, the reaction rate in Eq. (8) must be independent of the concentration. A linear regression approximation of carbon gasification $(Y)$ as a function of the residence time results in

$y=k \tau=0.11 \tau,\left(R^{2}=1\right)$

where $k$ is the reaction rate constant in $\left(\min ^{-1}\right)$. The problem with this approximation is that the residence time for needed for the maximal conversion cannot be determined.

The reaction order of zero in the kinetic equation has to be verified for other concentrations and shorter residence times. Lee et al. [7] studied the kinetics of glucose gasification in supercritical water. They adopted pseudo-first-order kinetics and found that the gas yield is independent of the residence time. They varied the temperature from 480 to $700{ }^{\circ} \mathrm{C}$. Using the Arrhenius approximation, a first-order kinetic equation was obtained. The difference between both kinetic approaches is maybe due to the region studied. At longer residence times, the first-order kinetics may also be interpreted as zero-order kinetics, because the conversion increases linearly with longer residence time. For a better description of the kinetics, experiments have to be performed at lower conversion.

At space times longer than $8 \mathrm{~min}$, the gas composition did not change with space time, as it is shown in Table 3. At shorter residence times, methane and ethane concentration is reduced with increasing $\mathrm{CO}$ and hydrogen concentration, which indicates that longer residence times are needed for methane production. The increase of the hydrogen concentration and decrease of the gasification yield with shorter residence time result in an almost constant hydrogen yield.

When studying the kinetics of supercritical water gasification of corn silage, the residence time dependence has to be 
Table 3

Gas concentration as a function of the space time, $T=973 \mathrm{~K}, p=25 \mathrm{MPa}$ for corn silage of $5 \mathrm{wt} \%$ (dry matter)

\begin{tabular}{llllll}
\hline $\begin{array}{l}\text { Space } \\
\text { time (min) }\end{array}$ & $\begin{array}{l}\mathrm{CH}_{4} \\
(\mathrm{vol} \%)\end{array}$ & $\begin{array}{l}\mathrm{CO}_{2} \\
(\mathrm{vol} \%)\end{array}$ & $\begin{array}{l}\mathrm{H}_{2} \\
(\mathrm{vol} \%)\end{array}$ & $\begin{array}{l}\mathrm{C}_{2} \mathrm{H}_{6} \\
(\mathrm{vol} \%)\end{array}$ & $\begin{array}{l}\mathrm{CO} \\
(\mathrm{vol} \%)\end{array}$ \\
\hline 3.27 & 14.98 & 42.89 & 33.97 & 2.61 & 2.80 \\
5.05 & 17.69 & 39.71 & 34.37 & 3.58 & 1.18 \\
7.27 & 17.09 & 43.83 & 31.89 & 4.20 & 0.62 \\
8.38 & 20.34 & 42.88 & 29.41 & 4.75 & 0.72 \\
10.17 & 18.75 & 43.86 & 29.70 & 4.80 & 0.74 \\
12.66 & 19.15 & 43.95 & 29.59 & 4.68 & 0.76 \\
16.82 & 20.50 & 43.11 & 29.68 & 4.34 & 0.82 \\
\hline
\end{tabular}

studied at different temperatures. In Fig. 4, the influence of the temperature and the residence time is illustrated.

According to Fig. 4, temperature influences notably the gasification yield. The temperature increase from 923 to $973 \mathrm{~K}$ improves the gas production by $20 \%$. The increment in the gasification yield from 773 to $973 \mathrm{~K}$ is more than $60 \%$. From the temperature variation in Fig. 4, it is obvious that the gasification yield of real biomass in supercritical water could reach $100 \%$ (within the experimental error) when the temperature is $973 \mathrm{~K}$. Decreasing the temperature deteriorates the gas production. With the new reactor configuration the gasification yield of corn silage was improved and was higher than by clover grass and corn starch.

At each temperature, the gasification yield increases with a longer residence time. The slopes of the curves change with temperature. The increase of the gasification yield as a function of the space time is steeper at higher temperature, which means that the reaction rate constant increases with temperature, as was expected from the Arrhenius equation.

The gas composition also changes with temperature. More hydrogen is produced at higher temperature. Hardly any hydrogen production has been observed at $773 \mathrm{~K}$. At this temperature, the CO concentration was about $15 \mathrm{vol} \%$. At $973 \mathrm{~K}$, however, it was less than 1 vol.\% as it is shown in Fig. 5. Increasing temperature promotes $\mathrm{CO}$ conversion by the water-gas shift reaction [4,7], although it is known that the water-gas shift reaction is exothermic and the thermodynamic equilibrium leads to $\mathrm{CO}$ formation at higher temperatures in the gas phase. Sato et al. [4] studied the water-gas shift reaction under non-catalytic conditions in supercritical water. They found that $\mathrm{CO}$ conversion was improved with increasing temperature. Lee et al. [7] observed that the production of CO

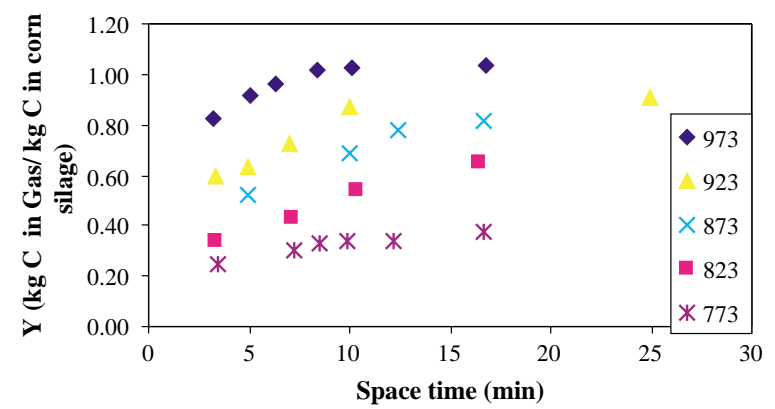

Fig. 4. Temperature influence on gasification yield $(Y)$ in the supercritical water gasification of corn silage at $p=25 \mathrm{MPa}$ and $5 \mathrm{wt} \%$ dry matter.

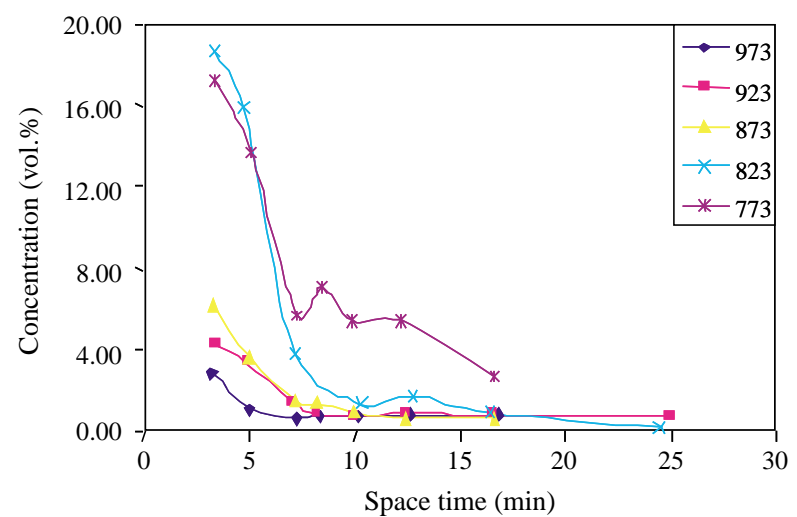

Fig. 5. Temperature influence on the $\mathrm{CO}$ concentration in the gas product during the supercritical water gasification of corn silage at $p=25 \mathrm{MPa}$ and $5 \mathrm{wt} \%$ dry matter.

in the conversion of glucose in supercritical water was constant between $783-933 \mathrm{~K}$. Further increase in the temperature abruptly improved $\mathrm{CO}$ conversion by the water-gas shift reaction. They considered this effect a result of a fast-type water-gas shift reaction. The higher conversion of $\mathrm{CO}$ observed in supercritical water with increasing temperature could also be explained by the methane production reaction, which is improved at higher temperatures.

At higher temperature, methane production increases, whereas the $\mathrm{CO}_{2}$ content in the gas decreases. At $773 \mathrm{~K}$, the methane content is less than $10 \%$ and it increases up to $20 \%$ at $973 \mathrm{~K}$. This increase with temperature and the increase in hydrogen concentration could be explained by the formation of methane from both $\mathrm{CO} / \mathrm{CO}_{2}$ and directly from the reacting biomass.

Concentration of gases with more than two C-atoms (propane, butane, etc.) was higher at lower temperatures. The energy needed to crack these hydrocarbons is not available at a temperature of $773 \mathrm{~K}$. These higher hydrocarbons have not been measured at $873 \mathrm{~K}$. Obviously, they react with water and are reformed to $\mathrm{CO}_{2} / \mathrm{H}_{2}$.

\section{Conclusions}

It was demonstrated that the gasification of real biomass components (clover grass and corn silage) in supercritical water was possible without the separation of the metals and other elements present in the natural biomass. Only a reduction of the solid particle size was necessary.

Potassium, up to a concentration of $500 \mathrm{ppm}$, influences the gasification of model biomass. Further addition of potassium did not improve the gasification yield. The addition of potassium has no effect in the gasification of potassiumcontaining natural products.

The gasification of biomass in supercritical water is independent of the pressure, but is significantly influenced by the temperature. Almost total conversion can be achieved at $973 \mathrm{~K}$. At lower temperatures, the gasification yield decreased to a level where hardly any gas was produced (at $T=773 \mathrm{~K}$ ). The gas composition also changes with temperature. Higher 
temperature leads to higher hydrogen production. At $773 / 823 \mathrm{~K}$, propane and butane are formed. At temperatures higher than $873 \mathrm{~K}$, light hydrocarbons like propane and butane are reformed to hydrogen and carbon dioxide or cracked to methane and ethane. The amount of $\mathrm{CO}$ in the gas product decreases with increasing temperature. The $\mathrm{CO}$ concentration is less than $1 \%$ at temperatures above $873 \mathrm{~K}$. This reduction of the $\mathrm{CO}$ content in the gas phase and the increase of hydrogen can be explained by the acceleration of the water-gas shift reaction with increasing temperature under supercritical conditions of water, although the thermodynamic equilibrium promotes $\mathrm{CO}$ formation at higher temperatures.

The increase in residence time improves the gasification yield and the gas production up to a certain value, which depends on the temperature. If the residence time is longer than this value, gasification yield does not increase. The linear increase of the gasification yield with the residence time can be approached with zero-order reaction kinetics. The kinetics have to be confirmed for other biomass concentrations. It is expected that the concentration does not influence the gasification yield. The gas composition varies with the residence time. The hydrogen and carbon monoxide contents increase at shorter residence times, whereas the methane and ethane contents in the gas phase decrease. To model component production as a function of residence time, a more complicated kinetic approach has to be applied. More experiments at shorter residence times remain to be performed to determine the reaction kinetics of the process.

\section{Acknowledgements}

The authors would like to appreciate the contributions of Miss V. Siriwongrungson, Mr. A. Dominguez, and Miss J. Stahl to the experimental work. Thanks go to Mr. Drexler for the preparation procedure of the educts, to Mr. K. Weiss for the mechanical work during the experiments, and to Dr. Diem and Dr. Kruse for discussions of the results.

\section{References}

[1] Yoshida Y, Dowaki K, Matsumura Y, Matsuhashi R, Li D, Ishitani H, et al. Comprehensive comparison of efficiency and $\mathrm{CO}_{2}$ emissions between biomass energy conversion technologies-position of supercritical water gasification in biomass technologies. Biomass Bioenergy 2003;25: 257-72.

[2] Calzavara Y, Joussot-Dubien C, Boissonnet G, Sarrade S. Evaluation of biomass gasification in supercritical water process for hydrogen production. Energy Convers Manage 2005;46:615-31.
[3] Matsumura Y. Evaluation of supercritical water gasification and biomethanation for wet biomass utilization in Japan. Energy Convers Manage 2002;43:1301-10.

[4] Sato T, Kurosawa S, Smith RL, Adschiri T, Arai K. Water gas shift reaction kinetics under noncatalytic conditions in supercritical water. J Supercrit Fluids 2004;29:113-9.

[5] Kruse A, Meier D, Rimbrecht P, Schacht M. Gasification of pyrocatechol in supercritical water in the presence of potassium hydroxide. Ind Eng Chem Res 2000;39:4842-8.

[6] Antal MJ, Allen S, Schulman D, Xu X. Biomass gasification in supercritical water. Ind Eng Chem Res 2000;39:4040-53.

[7] Lee I-G, Kim M-S, Ihm S-K. Gasification of glucose in supercritical water. Ind Eng Chem Res 2002;41:1182-5.

[8] Hao XH, Guo LJ, Mao XM, Chen HJ. Hydrogen production from glucose as a model compound of biomass gasified in supercritical water. Int J Hydrogen Energy 2003;28:53-64.

[9] Sinag A, Kruse A, Rahtert J. Influence of the heating rate and the type of catalyst on the formation of key intermediates and on the generation of gases during hydropyrolysis of glucose in supercritical water in a batch reactor. Ind Eng Chem Res 2004;43:502-8.

[10] Matsumura Y, Nagata K, Harda M, Kikuchi Y. Improvement of supercritical water gasification efficiency by increasing feedstock heating rate H2-age: When, Where, Why Pisa, May 16-19. Italian Association of Chemical Engineering; 2004.

[11] Idea T, Matsumura Y. Gasification of cellulose, xylan and lignin mixtures in supercritical water. Ind Eng Chem Res 2001;40:5469-74.

[12] Sato T, Osada M, Watanabe M, Shirai M, Arai K. Gasification of alkylphenols with supported noble metal catalyst in supercritical water. Ind Eng Chem Res 2003;42:4277-82.

[13] Minowa T, Zhen F, Ogi T. Cellulose decomposition in hot compressed water with alkali or nickel catalyst. J Supercrit Fluids 1998;13:253-9.

[14] Kruse A, Abeln A, Dinjus E, Kluth M, Petrich G, Schacht M, et al. Gasification of biomass and model compounds in hot compressed water. GVC-Fachausschuss 'High Pressure Chemical Engineering'; 1999.

[15] Saisu M, Sato T, Watanabe M, Adschiri T, Arai K. Conversion of lignin with supercritical water-phenol mixtures. Energy Fuels 2003;17:922-8.

[16] Osada M, Sato T, Watanabe M, Adschiri T, Arai K. Low temperature catalytic gasification of lignin and cellulose with a ruthenium catalyst in supercritical water. Energy Fuels 2004;18:327-33.

[17] Scheffer K. Biomasse-gespeicherte Sonnenenergie aus der Vielfalt der Pflanzenarten-Potenziale, Bereitstellung, Konversion. FVS DGS Themen 2000;34-9.

[18] Yu D, Aihara M, Antal MJ. Hydrogen production by steam reforming glucose in supercritical water. Energy Fuels 1993;7:574-7.

[19] Boukis N, Diem V, Habicht W, Dinjus E. Methanol reforming in supercritical water. Ind Eng Chem Res 2003;42:728-33.

[20] Sinag A, Kruse A, Schwarzkopf V. Key compounds of the hydropyrolysis of glucose in supercritical water in the presence of $\mathrm{K}_{2} \mathrm{CO}_{3}$. Ind Chem Eng Res 2003;42:3516-21.

[21] Boukis N, Galla U, Diem V, D’Jesús P, Dinjus E. Hydrogen production from biomass in supercritical water H2-age: When, Where, Why Pisa, May 16-19. Italian Association of Chemical Engineering; 2004.

[22] Feng W, Van Der Kooi HJ, Arons JDeS. Phase equilibrium for biomass conversion processes in subcritical and supercritical water. Chem Eng J 2003;98:105-13. 